\title{
El fascismo en la pantalla: Vincere (Italia, Bellochio, 2009)
}

\section{Marzorati, Zulema; Pombo, Mercedes [ver currículum del autor, docente de la Facultad de Diseño y Comunicación]}

Resumen: Vincere constituye una mirada oblicua sobrela Italia fascista, una película realizada a partir de la figura de Ida Dalser, amante de Benito Mussolini y madre de su primogénito Benito Albino, nacido en 1915. Tanto Ida como su hijo no figuran generalmente en los libros que recrean los acontecimientos que hacen al fascismo histórico.

Bellocchio los visibiliza mostrando sus vidas trágicas, encerrados hasta su muerte en hospitales psiquiátricos para evitar el conocimiento de una relación extramatrimonial que limitaría al Duce su carrera hacia el poder.

El film constituye una parábola biográfica a través de la cual se explora las marcas y huellas que relacionan la trayectoria individual de Dalser con los orígenes, consolidación y caída del fascismo. Y como todo cine histórico, reconstruye hechos del pasado para abordar el presente de Italia resignificado.

Palabras claves: Italia - Fascismo - Ida Dalser - Mussolini - Cine histórico.

$\left(^{*}\right)$ Doctora en Ciencias Sociales (UBA). Magister en Ciencias Sociales con orientación en Historia (Flacso). Docente e investigadora (UBA). Actualmente investiga las representaciones de la ciencia en documentales argentinos, habiendo publicado diversos artículos sobre esta temática.

${ }^{* *}$ Licenciada y Profesora en Enseñanza Media y Superior en Artes Plásticas (UBA). Docente, investigadora y fotógrafa. Actualmente investiga sobre fotografía argentina contemporánea dentro del marco del Programa de Investigación de la Facultad de Diseño y Comunicación, Universidad de Palermo.

Introducción
Cuadernos del Centro de Estudios de Diseño y Comunicación Nº 68

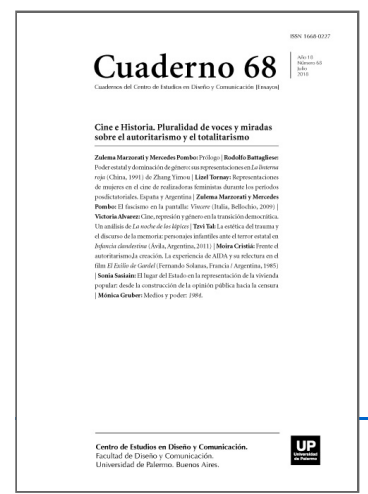

ISSN: 1668-0227

Cine e Historia.

miradas sobre el

autoritarismo y el

totalitarismo

Año XVIII, Julio 2018, Buenos Aires, Argentina | 148 páginas

descargar PDF

ver índice de la publicación

Ver todos los libros de la publicación

compartir en Facebook

Esta obra está bajo una Licencia Creative

Commons Atribución-NoComercial-

Compartirlgual 4.0 Internacional
Pluralidad de voces y 
Vencer, vencer, vencerVenceremos en tierra cielo y marEs la consigna de una suprema voluntad(Canción fascista Vincere)

El término fascismo describió desde su origen un particular sistema político de un área geográfica específica y en un período delimitado de tiempo centrado en Europa entre las dos guerras mundiales, una etapa que De Felice denomina fascismo histórico (De Felice, 1979, p. 13). Así, durante un cuarto de siglo (1919-1945), el fenómeno fascista, basado en una fuerte ideología nacionalista, el poder personal de Benito Mussolini1 y la violencia, se impuso en Italia. La crisis de la posguerra, las dificultades económicas y sociales y el temor ante la expansión de la revolución social iniciada en Rusia, facilitaron las condiciones para el triunfo de esta ultraderecha2 .

Con respecto a las interpretaciones sobre qué fue el fascismo, Bobbio (2006) considera que hay cuatro principales. En primer lugar la interpretación liberal propia de los conservadores italianos que considera al fascismo, desde su inicio, como un movimiento ajeno a la historia de Italia, fácilmente extirpable y desarrollado en circunstancias absolutamente excepcionales. Es decir que fue un paréntesis como lo plantea Benedetto Croce, correspondiente a un período de disminución de la conciencia de libertad.

Frente a esta interpretación de la derecha, se contrapone la radical, propia de la izquierda laica y democrática, en la que el fascismo sería la lógica e inevitable consecuencia de una serie de desarrollos propios de algunos países como Italia y Alemania. Con esto se hace referencia a la unificación tardía (1870) de estos países, que trajo retraso y fragilidad en el desarrollo económico. En ellos la burguesía se desarrolló en forma patológica, recurriendo a alianzas antiliberales y antidemocráticas para afirmar su propio predominio.

En tercer lugar -y primera en el orden cronológico ya que aparece en la Tercera Internacional (1922)- estaría la interpretación marxista que ve al fascismo como un agente violento y dictatorial del capitalismo de la gran burguesía como respuesta a la temida revolución proletaria y al ascenso de las masas populares hacia la conquista del poder político y económico.

Una cuarta interpretación considera que el fascismo fue la reacción de la pequeña burguesía, frustrada por las consecuencias económicas de la Primera Guerra Mundial. Fueron los integrantes de las clases medias, faltas de ideales propios, quienes integraron las escuadras fascistas. (Bobbio, 2006, pp. 75-77)

El objetivo de nuestro trabajo es analizar las representaciones del fascismo en Vincere3 donde interactúan distintos recursos del arte, la música, el documental y el cine de ficción, como un modo de narrar visualmente la relación de Mussolini con el poder y el pueblo italiano. Registros tan disímiles como el melodrama, la estética futurista, la ópera, los himnos partidistas, los noticieros cinematográficos y el cine dentro del cine son algunos de los elementos visuales y sonoros que utiliza Bellocchio4 para referirse a este proceso histórico y político.

En el texto fílmico se narra la historia de Ida Dalser5, amante de Mussolini desde 1913 con quien tuvo un hijo, Benito Albino, en 1915. La relación finalizó en 1917 y tanto Ida como Benito estuvieron ocultos por la historia italiana. La odisea que ella sufrió para lograr el reconocimiento legal de esta relación por la que había entregado su corazón y sus bienes, constituye el centro de la trama. 
En las biografías sobre Mussolini apenas si se hace mención a este tema. La vida trágica de ambos, nunca antes contada, se hizo visible cuando los periodistas Fabrizio Laurenti y Gianfranco Norelli6 realizaron el documental El secreto de Mussolini (Italia, 2010) que reconstruye el caso con las escasísimas evidencias disponibles (fotos, cartas, entrevistas) y prueba con estos testimonios y documentos la realidad de los hechos acontecidos.

En Vincere, el relato está estructurado como una tragedia que puede dividirse en dos grandes actos: en el primero se abordan los años en que Mussolini y Dalser empiezan su apasionada relación amorosa; en el segundo, la época del desencuentro y la desgracia en la que se juega el destino de lda y por extensión,el de Benito Albino. Para ocultarlos de la sociedad, madre e hijo mentalmente sanos, fueron internados por orden de Mussolini en instituciones psiquiátricas donde murieron sin tener la oportunidad de recobrar su libertad. Como sostiene Quintana, en las películas de Bellocchio muchas veces hay un personaje femenino que actúa como catalizador para acabar penetrando en el lugar oscuro de una institución, un grupo o un movimiento (Quintana, 2010). Así, la historia de la vida privada de Ida Dalser permite explorarlos orígenes y consolidación del fascismo e indagar en cómo se conforman las locuras individuales y sociales. Mussolini representa el poder y su esposa e hijo no reconocidos la resistencia, pero también la locura atrapados en el contexto de un estado demencial que caracterizaba al Duce. Los films de ficción son altamente reveladores de tensiones y de problemáticas sociohistóricas. Como documentos de la historia social, las imágenes cinematográficas colaboran en la comprensión de la sociedad en que fueron realizadas. Aunque reconstruyen hechos del pasado, esos eventos se conectan con las circunstancias contemporáneas en las que están inmersos (Sorlin, 1980). Y como todo cine histórico, Vincere aborda acontecimientos pasados, pero sólo (ineludiblemente) para hablar del presente resignificado.

\section{El poder hipnótico de Mussolini}

Desde 1908 Mussolini militó en el socialismo y hasta 1914 se encontraba dentro de la corriente más radical y revolucionaria del Partido. En 1912 fue nombrado director del perió- dico Avanti desde donde expuso sus ideas pacifistas, antinacionalistas y antiimperialistas. El vínculo de Mussolini con el poder y el uso de la palabra como motor revolucionario y político aparece desde la primera secuencia cuando, envuelto en soberbia, desafía a Dios: "Si dios existe que me pulverice". Pasan unos minutos frente al silencio del público y, cómo nada sucede, sonríe triunfante.

El poder y la efervescencia de las masas son protagonistas en esta primera etapa del relato, junto con la agitación propia del desarrollo industrial y el concepto de modernización que se vive en ese momento. Esto queda reflejado a través de la estética futurista utilizada desde el comienzo del film. Se incorporan imágenes de archivo de la época en blanco y negro, donde se van superponiendo imágenes que aluden al movimiento de una gran ciudad, inmersa en la productividad de la industria y la publicidad de los carteles luminosos que alientan al consumo. Además queda en evidencia esta estética y su ideología cuando se ven chimeneas de fábricas combinadas con torres de iglesias que connotan el enfrentamiento entre el socialismo y la curia. Las escenas están impregnadas por esta vanguardia artística y su visión del mundo. También el uso de la palabra GUERRA en mayúscula donde se plantea la dualidad entre la intención de paz y la realidad de la guerra.

El futurismo fue un movimiento de vanguardia nacido en Italia en 1909 a partir del manifiesto de su mentor Filipo Marinetti, dado a conocer en el periódico Le Figaro ese mismo año, donde los artistas se oponían a la rigidez y estatismo de los sistemas anteriores. Embelesados por el progreso se proponían reflejar en sus obras el 
dinamismo y movimiento de la modernidad. Buscaban generar nuevos caminos estéticos, donde quedara representada la belleza de las maquinarias y de la energía de la guerra. Como plantea Marinetti en el Manifiesto futurista: "La guerra es la única higiene del mundo (...) No existe belleza alguna si no es en la lucha. Ninguna obra que no tenga un carácter agresivo puede ser una obra maestra". (Le Figaro, 20 de febrero de 1909)

Hoy existen dos opiniones diversas acerca del futurismo: la primera es la que juzga esta estética como un puro movimiento artístico; la segunda es la que, en cambio, lo reduce a una simple premisa del fascismo. Se trata, sin embargo, de opiniones unilaterales que no tienen en cuenta las condiciones históricas en que surgió. En realidad el futurismo fue en sus orígenes un torbellino de ideas y de sentimientos diversos, en la que al menos, por lo que respecta a algunos de sus hombres, la voluntad de renovación no era ni puramente plástica ni puramente reaccionaria. Muchos futuristas procedían de las filas anarquistas y anarco sindicalistas y del nacionalismo. (De Micheli, 1967, p. 231)

En cuanto a la relación entre Mussolini y Dalser, ésta se inicia cuando él comenzaba su actividad política. Ella era una joven de origen burgués muy moderna para la época: había estudiado medicina estética en París y tenía su propio salón de belleza en Milán, lo que le dio notoriedad y dinero.

La primera parte del film muestra a Mussolini como un hombre de carne y hueso, enamorado de sus ideas revolucionarias y un hombre abierto a entablar un vínculo humano y amoroso con Ida. Desde un principio la relación se muestra asimétrica, donde vemos a Ida perder su propia identidad, bajo la mirada de Mussolini

Este vínculo incondicional con Benito se manifiesta tanto en la escena de 1907 cuando frente a un grupo de manifestantes que persiguen a Mussolini y sus compañeros, éste se refugia en sus brazos para salvarse de la situación o, como en el encuentro sexual de la pareja en 1914 donde se nota la pasión de ella en contraposición a la actitud de él, quien mira hacia el horizonte, una representación que por sobre todo muestra claramente su intención política hacia el futuro.

El poder persuasivo que tiene Mussolini sobre Ida muestra su personalidad hipnótica, dejando entrever su futuro liderazgo político. Ella no solo le da todo su patrimonio sino que también le ofrece su vida entera, colaborando financieramente para ayudarlo en la creación de un nuevo periódico: Il popolo d’Italia. Mussolini funda entonces este nuevo diario con el ayuda económica que también le ofrecen las corporaciones industriales intervencionistas (Tannenbaum, 1975) y el gobierno francés (Carsten, 1971)7 .

Otro punto interesante sobre la relación que entablan los personajes es que desde el comienzo, ellos queden en las penumbras. Tanto sus encuentros amorosos como sus desencuentros y falta de atención suceden en la oscuridad, vislumbrándose apenas sus gestos y miradas. Recién cuando ese amor queda declarado y ella le dice que está embarazada es que la iluminación cambia y pasa a ser directa.

La unión entre ambos continúa, siempre apoyada en el esfuerzo, en el amor de ella hacia él. Mientras tanto, vemos a la pareja legal de Mussolini, Rachel Guidi, con quien ya tenía una hija y con la que se casará en 1915.

Ida mantiene su amor incondicional mientras Mussolini sigue adelante con sus proyectos políticos, solo dejándose querer por ella. Una noche Benito le confiesa su miedo a la mediocridad y la necesidad que tiene de 
ser alguien importante, como lo fuera Napoleón. Ella, le ata los cordones en representación de entrega y sometimiento.

En 1914 nació el hijo de ambos, Benito Albino, que fue reconocido por Mussolini.

\section{¡GUERRA, GUERRA!}

El estallido de la Primera Guerra Mundial provoca un cambio en la ideología de Mussolini que pasa del neutralismo pacifista8 hacia posturas tendientes a la intervención en apoyo de la Triple Entente. Desde el Avanti escribe en octubre de 1914 un artículo claramente intervencionista y por eso es separado de su cargo y expulsado del Partido Socialista en noviembre.

Aparece la palabra SARAJEVO en mayúscula y en primer plano, seguido de GUERRA GUERRA, titulares superpuestos sobre imágenes a color. Vemos a los soldados marchando en movimiento, tal como en las obras futuristas del momento, otra vez marcando la relación entre esta vanguardia artística y las ideas violentas.

La exaltación de la máquina, del modernismo y de la velocidad que impulsa el futurismo italiano en el Manifiesto de 1911, acabó por identificarse con las tesis de la más activa burguesía del norte que quería la intervención en la guerra, contra la más retardataria burguesía agraria. (De Micheli, 1967, p. 237)

Italia entró en la guerra en 1915 y Mussolini sirvió en el frente, donde fue herido en 1917. Durante esos años le enviaba una pensión a Ida para su hijo Benito.

Al regresar lo llevaron a un hospital donde estaba cuidado/custodiado por su mujer, Rachele Guidi. Ella era una mujer iletrada, que cumplía con el rol de esposa tradicional, justo lo opuesto de Dalser.

Como sostiene Sánchez López, el rol privilegiado por el fascismo era el de casalinga (ama de casa), que no sólo tenía la función de favorecer el desarrollo demográfico y conservar la estructura familiar autoritaria, sino que ofrecía a las mujeres la posibilidad de integrarse socialmente a través de su misión materna (Sánchez López, 1995, p. 23). Con el argumento de que las mujeres eran incapaces de usar armas convirtiéndose automáticamente en ciudadanas de segunda, su papel se centraba en el hogar, donde vivían subordinadas al hombre.

La contracara de esto era Ida, una mujer independiente que no convenía a Mussolini para el logro de sus intereses políticos. Es por eso que él la repudiaba ya que, además su relación le traería problemas con la Iglesia Católica, institución que se mantuvo autónoma frente al poder hasta 1929.

Al momento de enterarse de la herida de Mussolini, Ida lo va a ver al hospital donde Rachele la enfrenta. Al fondo, entre las camas y los enfermos se ve una pantalla con escenas de Cristo y la Madonna, imágenes extraídas de la película Christus (Giulio Antamoro, 1916) que se contraponen con las de Mussolini y su esposa. Como un diálogo entre la imagen que está sucediendo de Mussolini herido, con su mujer a su lado y Cristo convertido en Jesús, como el salvador de la humanidad, Mussolini se transforma en ese Cristo crucificado que se ve en pantalla, deja de ser un hombre para convertirse en una idea. Desde esta escena Benito se esfuma de la película para convertirse en un personaje fantasma (solo aparece una vez más en la exposición futurista). Su presencia va a estar determinada por documentos audiovisuales de la realidad, noticieros o como sueño o 
recuerdo. El Cristo en la cruz, que se ve en la pantalla, actúa como alter ego de cómo se ve él mismo: Mussolini como el salvador de Italia, o cómo él creía (y quería) que lo considerara todo el pueblo italiano. Un nuevo Mesías.

Tras la convalecencia, Mussolini volvió a dirigir su diario y empezó a clamar por la necesidad de un hombre fuerte que terminara con los problemas nacionales. La crisis económica, social y política del país atrajo a muchos seguidores hacia el fascismo, movimiento autoritario que exaltaba la violencia.

El Partido Nacional Fascista (1921) tuvo el apoyo financiero del gran capital agrario e industrial italiano, que buscaba destruir la fuerza de los campesinos y obreros. En 1922, la Marcha sobre Roma organizada por Mussolini ante la amenaza de una huelga general, hizo que el rey Víctor Manuel III le encargara formar gobierno.

Mussolini, de hombre a imagen

Ida y Benito se encuentran en la exposición futurista de 19179 ; ella se muestra desesperada por acercarse pero él la rechaza rotundamente, dejando en evidencia su desprecio tanto hacia ella como hacia su hijo. Esta situación va creciendo hasta que en febrero de 1920 -por orden del Duce- Ida y Benito Albino son llevados a la casa de su hermana Adele, donde son vigilados día y noche10.

A partir de este momento Mussolini no aparecerá más representado por el actor Filippo Timi. Cuando Ida lo ve en la pantalla del cine, es una imagen de archivo, es el Duce ya convertido en dictador, una imagen - ídolo. Las imágenes ficcionales y documentales se combinan en la búsqueda de un estilo propio; donde conviven los actores y los protagonistas reales de la historia. El personaje de Benito desaparece para dar paso a las imágenes del dictador real, tomadas de fuentes de archivo.

Es llamativa la elección de Filippo Timi para personificar a Mussolini; al espectador le produce extrañamiento ya que el actor no es parecido al Duce. Estamos acostumbrados al Actor Studio que busca siempre actores que se acerquen fisonómicamente al personaje, o se los caracteriza para lograr una semejanza.

Otro punto interesante en este manejo con el personaje ficcional y documental, es que el actor que encarna al dictador en la primera mitad de la película será el que represente a su hijo Benito Albino cuando crece y lo imite en sus discursos políticos. Esto constituye un mecanismo de representación por el que el hijo no reconocido se mimetiza con el padre. Y se esfuerza por imitarlo en esos únicos momentos posibles: los discursos públicos ya que no existe ninguna posibilidad de un acercamiento entre hijo y padre en la intimidad de la vida privada.

Tannenbaum sostiene que el fascismo, como movimiento para la conquista del poder, se muestra generalmente despreciativo con las autoridades existentes y cambia al establecerse el régimen, realizando toda clase de esfuerzo por convertirse en totalitario. Otra diferencia que plantea el autor, es la que diferencia ideología y práctica: cuando busca el poder Mussolini se opone a todo lo instituido, pero en la práctica establece compromisos con el Ejército, la burocracia, la Iglesia y parte de la alta burguesía, y el énfasis puesto en el dinamismo de la juventud se convierte en mera retórica (Tannenbaun, 1975, pp. 13-14). Así se muestra claramente la alianza de Mussolini con el Vaticano, y cómo va cambiando desde el ateísmo hacia el apoyo papal para garantizar las riendas del gobierno11. 
En el cine de Bellocchio, los locos son los liberadores. Aquellos que para el resto de la sociedad son enfermos, aquí son héroes. Héroes involuntarios que desarticulan el discurso de los presuntamente cuerdos. Todo esto se encuentra condensado en la figura de Ida Dalser. Su fanatismo se convierte en elemento subversivo; el amor por el dictador se transforma en odio y persecución.

A lo largo de la película aparecen señales sobre su destino; se trata de fogonazos de una realidad que anticipa lo que ocurrirá después. Se ve a una mujer en primer plano, sola, sin ningún marco de referencia, casi estática. La única pista que se le brinda al espectador es su mirada y su actitud corporal, que por sus poses, sus gestos y vestimentas traen al recuerdo de una insana. Estas escenas-retratos se van sucediendo a lo largo de todo el film con pequeños y sugestivos cambios: la mujer que aparece en pantalla tiene cada vez una actitud más extraña, emparentada con alguien marginado de la sociedad, cada vez más parecida a una interna psiquiátrica.

El rol de Ida va siendo cada vez más solitario. Se va transformando en una mujer incomprendida a la que no le queda otra opción que ser institucionalizada. Esa escena - retrato de una mujer loca- cambia por una cámara subjetiva donde se ven los rostros de varias mujeres mirando hacia nosotros. Son las caras de sus posibles compañeras en el internado psiquiátrico. La película se adelanta en el tiempo, hacia el momento en que finalmente la encierren: el primer día de Ida en el psiquiátrico, su futuro hogar. Otra escena muy representativa de la locura y su relación con la sociedad del momento es cuando lda se encuentra con el psiquiatra, quien intenta ayudarla a salir de la institución y le dice que para eso ella debe callar. Es un encuentro de dos posiciones, acompañar el statu quo -callar y acompañar lo establecido, esperando que algún día eso cambie- o gritar la verdad más allá de sus consecuencias. Es un momento en donde Ida nos hace reflexionar acerca de quién es el loco, quién es el cuerdo: el psiquiatra proponiéndole que se quede tranquila, subrayando el rol de la mujer como ama de casa, o Ida intentando gritar al mundo su verdad y su pasión. Lo que quiere proclamar es su descontento contra el orden establecido, contra la injusticia de lo que está viviendo y contra la indiferencia que siente en el mundo que la rodea. Eso sería realmente la locura, la despreocupación del que no ve, no oye, no dice. La sensación que le genera al espectador es que si Ida no grita, si no dice su verdad,pierde su identidad, deja de sentirse como una mujer que tiene dignidad, que es pensante y luchadora. Se trata de una verdad individual pero también social, al abordar la historia de Ida con el Duce, el texto fílmico también hace referencia a una falta de franqueza y coraje del pueblo italiano. Ida es recluida por haber intentado revelar con su verdad el lado oscuro del fascismo.

En cuanto al cine dentro del cine, en el psiquiátrico se proyecta El Pibe (1921),una de las más famosas películas de Chaplin, en la está presente el tema de los hijos abandonados e ilegítimos. El relato, de corte melodramático, conmueve a Dalser haciéndola llorar desconsoladamente. Sólo se tranquiliza cuando Chaplin rescata al niño y éste es devuelto a su madre. Con este final feliz se repara en el film lo que no ocurre con Ida y su hijo en la realidad.

A la par que sucede esta escena, vemos a su hijo -también internado, encerrado, en un reformatoriodesafiando a los directivos. Se esconde, tira al piso la escultura de la cabeza del Duce y la rompe en su afán por demostrar su inconformidad.

A partir de este momento, la locura de Benito Albino se va a sostener a lo largo del film. Él también se enfrenta a la locura, imitando a su padre de una manera peculiar. Son varias las escenas en que aparece esa fascinación - 
mezcla de amor, odio y desencuentro- que siente el hijo por su padre, y que se manifiesta en una imitación gestual y verbal casi grotesca.

Poética visual y sonora

En Vincere se dirime una historia que es a la vez personal y colectiva. El relato se sostiene tanto desde la imagen como desde el sonido posibilitando las distintas lecturas que el espectador puede hacer del mismo. Ida Dalser representa el encantamiento del pueblo italiano por el Duce: una fascinación que oscila entre la locura, el misterio y la resistencia. Bellocchio utiliza claramente los recursos del arte a lo largo de la película, tanto la estética futurista -ligada a la historia de Italia y su idiosincrasia- como por la ópera, que acompa- ña todo el film y se refiere a pasiones humanas con finales trágicos.

Hay escenas donde la metáfora visual es lo central, por ejemplo cuando Benito se refugia en los brazos de Ida frente a una persecución en una manifestación política. Ella se encuentra en la oscuridad de un paredón, allí se dan un beso antes de que él se vaya y al mirar sus manos lda las nota manchadas de sangre. Esta vuelve a repetirse otra vez en el film. Allí está representada la contracara de la revolución socialista, simbolizando la violencia del posterior régimen fascista.

También se ven escenas que aluden a la falta de libertad de Ida, las cuales se resuelven de un modo visualmente poético. Por ejemplo la escena de Ida trepada en la rejas, mirando hacia el horizonte, hacia un cielo abierto; mientras ella se encuentra enjaulada como un tigre. Por otra parte, las cartas que escribe y arroja al exterior, aparecen como un elemento de cruce entre la libertad y el encierro; como una necesidad de comunicación que queda trunca y que se ve reflejada en varias escenas de la película. Por ejemplo cuando se la ve a Ida tirándolas a través de la ventana del psiquiátrico, algunas dirigidas a Mussolini, otras al rey y al papa; cartas que quedarán en el silencio. Visualmente esta escena del ventanal es muy representativa de la inutilidad de los esfuerzos de Ida por hacerse escuchar. La nieve cae en el exterior mientras ella se va trepando y la luz como un foco que se apaga- va desdibujando a los personajes.

En cuanto al sonido, el film está construido desde la poética operística donde se muestran pasiones humanas con finales trágicos. La banda sonora, a cargo del compositor Carlo Crivelli, está conformada por escenas como actos de ópera, organizados en forma teatral y espectacular. Así la ópera, tan importante en Italia, está siempre presente en la forma en que el film se articula; en particular resuenan los ecos de Aída y Rigoletto de Giuseppe Verdi y la inclusión de fragmentos de Tosca de Giacomo Puccini.

Como un modo de expresionismo sonoro, en varias escenas el ritmo avanza con fuerza, como cuando se declara la guerra, representando la violencia de principios de siglo. También está presente el cántico de los niños que se burlan de la Mussolina y, se recuperan himnos partidistas como la marcha La legenda del Piave, All armi, siami fascisti y Vincere, todas canciones patrióticas nacionalistas. La música y los versos de Vincere se escuchan al comienzo y al final del film, aunque la cabeza aplastada de Mussolini se aleje del triunfo victorioso al que hace referencia la canción fascista.

Además de esa música incidental extradiegética, Rodríguez señala una música clave, no de la película, sino en la película: es la que tocan al piano durante las funciones de cine mudo cuando se proyecta un noticiero. Sobre la pantalla se ven escenas de la Primera Guerra Mundial en la que chocan los dos bandos en pugna y la 
contienda se extiende en la sala de cine donde explota una pelea entre fascistas y socialistas, mientras el piano sigue sonando. (Rodríguez, 2010)

\section{Conclusión}

La historia de Ida y de su hijo permite indagar en el rol de Mussolini y sus vínculos con la política, la alta burguesía y la iglesia, en Italia. Un relato sobre locura y poder durante el período fascista, tomando a Ida como personaje central, para luego traspasarlo a todo el pueblo italiano.

Mussolini desconoce cualquier tipo de reciprocidad con el pueblo y con Ida. Esa veneración y ese culto que se le rinde no es un aspecto que le importe al Duce, él se siente por encima de todo eso. Él es Napoleón o es Cristo. Es un dictador lleno de poder que no debe rendir cuentas a nadie, ni siquiera por amor.

Ida puede ser ese pueblo traicionado. Como todos, fue seducida por Mussolini y llevada al paroxismo por su ímpetu delirante y belicoso. Dice Bellocchio en una entrevista: "Ida Dalser es testigo de todos los movimientos que atravesaron Italia en aquel momento, sobre todo el futurismo, y que me aportan a mí, en tanto realizador, soluciones, imágenes”. (Delorme, Sthéfane y Tessé, Jean-Philippe, 2010, p. 3)

Al final, es la propia Italia, como cuerpo, la que sucumbe junto a Dalser y Mussolini y a la ideología del fascismo. En los últimos planos, Dalser mira a la cámara, interpelando al espectador, mientras es llevada al psiquiátrico, del que no saldría nunca más. Su hijo, fruto de su relación con el dictador, acaba igual. Y mientras las estrofas de Vincere se pierden entre las imágenes de archivo que documentan la violencia, la destrucción y el fin de la guerra, el Mussolini hombre, que desafiaba a Dios al inicio, regresa, por última vez, para ver cómo su busto y su legado son pulverizados.

Con este film, Bellocchio arma un rompecabezas donde juega con fuentes de la época - diarios, fotos, cartas, registros cinematográficos documentales y de ficción-. Y a través de los diferentes entramados simbólicos produce una reflexión sobre las categorías políticas que circulaban y se resignifican en la sociedad italiana de hoy.

Notas

1. Benito Mussolini (Dovia de Predappio, Italia, 1883 - Giulino de Mezzegra, Italia, 1945). Periodista, político y dictador italiano. Primer Ministro desde 1922 (Marcha sobre Roma) hasta 1943, en que fue brevemente encarcelado. Con ayuda alemana se instaló en Salo como presidente de la República Social Italiana (gobierno títere de Hitler) entre 1943 y 1945, año en que fue fusilado por los partisanos.

2. Sobre el Fascismo ver: Stanley Paine (1998). Historia del fascismo. Buenos Aires: Planeta; Emilio Gentili (2005). La vía italiana al totalitarismo. Partido y Estado en el Régimen Fascista. Buenos Aires: Siglo XXI; Norberto Bobbio (2006). Ensayos sobre el Fascismo. Selección de textos, traducción e introducción: Luis Rossi. Universidad Nacional de Quilmes, Buenos Aires: Prometeo; Zeev Sternhell et al (2006). El nacimiento de la ideología fascista. Buenos Aires: Planeta.

3. Vincere: Intérpretes: Giovanna Mezzogiorno, Filippo Timi, Corrado Invernizzi, Fausto Russo Alesi, Michela Cescon, Pier Giorgio Bellocchio y Paolo Pierobon. 
4. Marco Bellocchio (Piacenza, Italia, 1939), integra el Ilamado realismo crítico italiano. Su irrupción en el mundo del cine con Las manos en el bolsillo (1965) promovió fuertes debates. Ha realizado películas políticas y de denuncia, habitualmente rodeadas de polémicas que le han hecho recibir ataques tanto de derecha como de izquierda. Entre sus principales filmes se encuentran: China está cerca (1967), En el nombre del padre (1971), La luna (1979), La condena (1991), La sonrisa de mamá (2002), Sorella Mai (2010) y Bella addomentata (2012).

5. Ida Dalser nació en Trentino, Italia en 1880. Amante de Mussolini, madre de su primogénito Benito Albino, Cuando reclamó por sus derechos, fue silenciada e internada en hospitales psiquiátricos. Primero fue internada en Pergine Valsugana, y luego en la isla de San Clemente en Venecia, donde falleció en 1937 por una hemorragia cerebral.

6. Fabricio Laurenti, un realizador italiano y Gianfranco Norelli, un periodista italoamericano fueron a Estados Unidos para encontrar documentos que no había en Italia.

7. Para Carsten, la mayoría de las opiniones autorizadas están hoy de acuerdo en que Mussolini se convirtió en un intervencionista, no porque fuera "comprado" por nadie, sino porque creyó que la guerra podría servir para sus objetivos subversivos en el interior (Carsten, 1971, pp. 34-35).

8. Italia permanece neutral hasta 1915. Caso único en Europa, el partido Socialista permanecía unido en su oposición a la guerra.

9. El fascismo, al transformarse en partido de gobierno, y por lo tanto, en partido del orden, dejó de sentir la necesidad de tener por aliada a la chusma vociferante de los futuristas. Era necesario declarar concluida la crisis posbélica y dar un fundamento histórico al nuevo Estado nacido de la Marcha sobre Roma (...) Hasta el arte exigía algo más sólido e imponente, algo que fuese digno de la romanidad, de la tradición milenaria, latina y mediterránea. Y así nació el Novecento, la Muestra de la Revolución Fascista; en suma, la restauración neoclásica, académica y conmemorativa en las artes. (De Micheli, 1967, p 239)

10. Benito Albino, siendo niño, fue secuestrado por las autoridades fascistas. Se le dijo que su madre había muerto y fue educado en un internado donde se encontraban los pupilos de la aristocracia italiana. Luego, enrolado en la marina, siempre bajo estricta vigilancia. Pero como insistía en que el Duce era su padre, fue internado en el asilo de Limbiate donde murió en 1942 a los 26 años, según algunas fuentes por marasmo (desnutrición).

11. Mussolini, primer ministro italiano, firma el Tratado de Letrán con el cardenal Pietro Gasparri , en nombre de la Santa Sede el 11 de febrero de 1929. Por el mismo se establecía reconocer la independencia y soberanía de la Santa Sede y ciudad del Vaticano, definiéndose así las relaciones civiles y religiosas entre el gobierno y la Iglesia italiana junto con una compensación por las pérdidas de la Iglesia en 1870.

Bibliografía

Bobbio, Norberto (2006). Ensayos sobre el fascismo. Buenos Aires: Universidad Nacional de Quilmes

Carsten, Francis (1971. La ascensión del fascismo. Barcelona: Seix Barral 
De Felice, Renzo (1979). Entrevista sobre el fascismo con Michael A. Ledeen. Buenos Aires: Sudamericana

Delorme, Sthéfane y Tessé, Jean-Philippe "Un melodrama futurista”. Entrevista con Marco Bellocchio. Cahiers du Cinema, España, $N^{\circ} 35$, junio 2010

De Micheli, Mario (1967). Las vanguardias artísticas del siglo XX. Madrid: Alianza

Tannenbaum, Edward R. (1975). La experiencia fascista. Sociedad y cultura en Italia (1922- 1945). Madrid: Alianza Quintana,Ángel. Cahiers du Cinema, №35, España, Junio 2010

Rodríguez, Marcos. "Violencia atonal”. El Amante №220, Septiembre 2010

Sánchez López Rosario "Mussolini, los jóvenes y las mujeres: La lisonja como estratagema”. Historia Social n 22, 1995, pp. 19-41

Sorlin, Pierre (1980). The film in History. Restaging the Past. Basil Blakwell. Oxford: Basil Blakwell

Abstract: Vincere is an oblique look at fascist Italy, a film made from the figure of Ida Dalser, lover of Benito Mussolini and mother of his firstborn Benito Albino, born in 1915. Both Ida and her son are not usually found in books that recreate the events that make historical fascism.

Bellocchio visibilises them by showing their tragic lives, locked up until their death in psychiatric hospitals to avoid the knowledge of an extramarital relationship that would limit the Duce in his race towards the power. The film is a biographical parable through which the marks and traces that link Dalser's individual trajectory with the origins, consolidation and fall of fascism are explored. And like all historical cinema, it reconstructs facts from the past to address the resignified Italy's present.

Key words: Italy - Fascism - Ida Dalser - Mussolini - historical cinema.

Resumo: Vincere constitui uma mirada indireta sobre a Itália fascista, um filme feito a partir da figura de Ida Dasler, amante de Benito Mussolini e mãe do seu primogénito Benito Albino, nascido em 1915. Tanto Ida como seu filho não aparecem geralmente nos livros que recreiam os acontecimentos que fazem ao fascismo histórico.

Bellocchio os faz visíveis mostrando suas trágicas vidas, trancados até sua morte em hospitais psiquiátricos para evitar o conhecimento de uma relação extramarital que limitará ao Duce sua carreira ao poder.

O filme é uma parábola biográfica através da qual se explora as marcas e pegadas que relacionam a trajetória individual de Dasler com os origens, consolidação e caída do fascismo. E, como todo o cinema histórico, reconstrói fatos do passado para abordar o presente resinificado da Itália.

Palavras chave: Itália - fascismo - Ida Dasler - Mussolini - cinema histórico.

El fascismo en la pantalla: Vincere (Italia, Bellochio, 2009) fue publicado de la página 39 a página50 en Cuadernos del Centro de Estudios de Diseño y Comunicación № 68 
